\title{
More Than Clothes Hangers: Cultural Intermediaries in the Field of Fashion
}

\section{Introduction}

This research focuses empirical attention on discussions of what cultural intermediaries do when they operate as arbiters of taste. Presently, consumer research conceptualises cultural intermediaries as marketplace actors who imbue cultural products with symbolic value and who consequently diffuse meanings to consumers (McCracken, 1986; Venkatesh and Meamber, 2006). In doing so intermediaries are said to legitimate the experiential consumption of material goods, services, ideas, behaviours. Yet, despite their significance in determining the authenticity of others' experiences (Smith Maguire and Matthews, 2012), unanswered questions remain as to how cultural intermediaries actually effect this process.

One explanation for the ambiguity around cultural intermediaries is that, as experts in their respective fields, they embody varying degrees of authority (capital) and are capable of different levels of performance (Woodward, 2006) through which they seek to influence others (Smith-Maguire and Matthews, 2012). Relatedly, value within cultural industries is often aesthetic. Indeed, value may derive in particular from the capacity of expert cultural intermediaries to legitimate experiential fantasies (Campbell, 1987), myths and cultural scripts (Alexander, 2004), thus preserving the illusio of their field (Bourdieu 1984). This value is underpinned by the belief that cultural work is special and mysterious and, as such, can only be undertaken by special and mysterious people (Beck, 2003; Nixon and DuGay 2002). Such thinking has led consumer researchers to characterise cultural intermediaries as 'merchants of mystique' and their influence on consumption a type of sorcery (Belk et al. 2003) and magic (Arnould, 2004). 
In an attempt to demystify cultural work of this kind we adopt the fashion industry as a context within which to better explore the complex relationships between cultural intermediaries and to explicate the embodied performances by which they influence each other. To follow, we present a review of the literature on cultural intermediaries within marketing and consumer research before turning attention specifically to fashion models. We argue that fashion models are culturally revered marketplace actors, noting how their performances allow them to become the "personification of the consumer's dream" (Venkatesh et al. 2010, 466). Following a discussion of methodology, we offer empirical coverage of the performances constitutive of the cultural mediation of hedonic fantasy. Finally, we conclude with a discussion and implications for the work.

\section{Cultural Intermediaries}

As traffickers of value and taste (Cronin, 2004) cultural intermediaries respond to the "new logic of the economy" (Bourdieu 2000, 310) described by Jensen (2002) as the 'dream society'. Faced with deflated interest in material belongings, consumers actively seek out affect-laden experiences that evoke a sense of vitality in their lives (Holbrook and Hirschman 1982; Firat and Dholakia, 1998; Pine and Gilmore 1999; Lanier and Rader, 2015). Campbell (1987) has described this new era of consumption as imaginative hedonism wherein value emerges from the emotionally pleasurable experiences elicited in fantasy. Here, the end consumer is conceptualised as a 'dream artist' who negotiates experiential fantasies as though they were real (Campbell, 1987).

Cultural intermediaries are integral to value formation in capitalist consumer society as a result of their ability to shape collective consciousness by inhabiting and mobilizing legitimated ideal subject positions in the marketplace. Their expertise encourages affective investment in the cultural belief system and hails hedonistic followers (Holbrook and Hirschman, 1982) to imagine themselves as or in relation to the reality performed (Berger, 1972). While few definitions exist, the cornerstone of 
work on cultural mediation is provided by Pierre Bourdieu (1993; 1984), who describes intermediaries as those involved in the production of symbolic goods and services:

"occupations involving presentation and representation (sales, marketing, advertising, public relations, fashion, decoration and so forth) and in all the institutions providing symbolic goods and services. These include the various jobs in medical and social assistance ... and in cultural production and organisation” (Bourdieu 1984, 359).

However his list of potential intermediaries is sprawling and includes those in cultural industries such as television, journalism and radio, groups in marketing, advertising as well as medical and social assistance sectors. In their seminal review of the concept, Smith-Maguire and Matthews (2012) note the lack of a common foundation upon which we might advance our understanding of cultural intermediaries. Further, they argue that multiple conceptualisations have produced "a conceptual muddle that fails to assist in unpacking the division of labour involved in the construction of cultural goods" (Smith-Maguire and Matthews 2012, 552). Such is the ubiquity of the term 'cultural intermediary' that Smith-Maguire and Matthews (2012, 552) provoke: “Are we all cultural intermediaries now?" The shifting landscape of consumer culture over the last three decades has ensured that we all have a hand in the formation of value and has even seen traditional end consumers occupying an important role as contributors to brand value (Cova et al., 2011). As such, to mitigate any confusion we must consider cultural intermediaries as contextualised market actors rather than attempt to offer an all-inclusive categorisation of their influence (Molloy and Larner, 2010). Work must therefore pay attention to the heterogeneous conditions of their existence in the market and the relation between any intermediary's habitus and these conditions (Bourdieu, 1984).

As Smith-Maguire and Matthews $(2012,552)$ contend, these conditions are material and discursive constructs ${ }^{1}$ that allow these market actors to do cultural mediation; that is, to "impact upon notions of what and thereby who, is legitimate, desirable and worthy, and thus by definition what and who is

\footnotetext{
${ }^{1}$ location within the field, social and historical specificity of the cultural field, commodity circuits and the field-specific devices that facilitate this process.
} 
not." For Entwistle (2006) the processes of mediation have come under less scrutiny than the identities of mediators. While identity is important, it is but one part of a complex mix of cultural mediation (Cronin, 2004). To better appreciate this process, then, research must dispense with the traditional dichotomy between production and consumption (Negus, 2002), instead foregrounding the productive capacity of consumption (Firat and Venkatesh, 1995). Smith Maguire and Matthews (2012) provide a framework through which to better access this contextual reality of cultural mediation. This framework incorporates the three categories of framing, expertise and impact.

Framing helps to conceptualise the mystique of intermediaries as grounded in heterogeneous and aesthetically stylised forms of consumption. It is a process whereby cultural intermediaries mobilise aestheticised styles of consumption that conform with notions of aesthetic taste within a particular field (Dion and Arnould, 2011). Its purpose is to legitimate goods (material goods, ideas, services, behaviours etc.) as desirable and worthy of attachment (Smith Maguire and Matthews, 2012) by intended receivers. Discussions within consumer research tend to assume that the consumer is the intended receiver of such orchestrated experiences (Dion and Arnould, 2011). However, we argue that this is to oversimplify the cultural mediation process. As Smith Maguire and Matthews (2012) indicate, each network possess its own unique characteristics and cultural conditions made up of human and non-human actors that must be negotiated during the framing process. Based on this argument, broadly speaking, we conceptualise cultural intermediaries here as contextualised marketplace actors whose performances are designed to obfuscate any perceived distinction between art and commerce. In mediating between economy and culture, more specifically, intermediaries influence other market actors, thereby authenticating and diffusing branded, fantasy experiences.

While imagination and fantasy are often conflated terms, the distinction is important to understanding what cultural intermediaries do during framing. While both deal in fictional worlds, imagination is grounded in lived reality in that it provides meanings that help individuals make sense of their social 
world (Maes 2011; Jenkins et al. 2011). Fantasy on the other hand is a conduit through which our desires are constructed and legitimated (Shankar et al. 2006; Jenkins et al. 2011). It offers complete emancipation from lived reality and the creation of another world where more romantic meanings, beliefs and identities are authenticated (Arnould and Price 1993; Belk and Costa 1998; Lanier and Rader 2005; Goulding and Saren 2009). The dissemination of an authentic fantasy during framing encourages further mediation by other intermediaries in the field.

Smith Maguire and Matthews (2012) also note how expert orientation differentiates between cultural intermediaries of the same commodity chain. This helps explain the asymmetry of influence and cultural authority held by intermediaries within the same cultural field. The authors observe two main types of expertise - professional and personal. Importantly, the two are not mutually exclusive as developing professional expertise (e.g., field specific awards, accreditations, reverence etc.) is contingent on personal expertise (e.g., subjective dispositions, a unique aesthetic orientation, and cultural capital). A stock of both professional and personal expertise augments an intermediary's ability to work with field-specific devices thereby increasing their capacity to influence others.

Impact refers to the intensity with which cultural intermediaries constitute and mobilise categories of cultural legitimacy and disguise the arbitrariness of desirability. Thus the ultimate impact of cultural mediation is in constructing enduring social relations and canons of aesthetic taste within a cultural field that serve to reaffirm the ideological constructs upon which value in the field depends. This process is most evident and ripe for empirical exploration in the field of fashion.

\section{The Field of Fashion}

Fashion is best conceptualised as the commodification and sale of dreams. It exemplifies a field of restricted production (Bourdieu, 1995; Rocamora 2002a; Rocamora 2002b; Entwistle and Rocamora 2006) in that aesthetic value derives from experiences legitimated as intrinsically pure, esoteric, abstract and difficult to rationalise cognitively. In this field, aesthetic value and cultural legitimacy 
supersede a desire for economic gain (Wagner, 1999). Furthermore, this value does not come from nowhere, but rather, is generated from within the field (Venkatesh and Meamber, 2006) and presided over by powerful agents (such as designers, editors, critics, bookers, etc.) with years of experience in that field (Preece et al., 2016; Mears, 2010).

During mediation events (e.g., fashion shows, photo shoots, parties, fashionable gatherings, general sociality within the field etc.), cultural commodities become legitimated through stylistic and esoteric consumption performances where intermediaries "harness symbolic codes, narratives and objects to achieve certain ends", (Woodward 2006, 264). Importantly, these events not only ensure the production of competent consumers, but also further bestow intermediaries with a mark of distinction and the cultivated disposition to decipher and enjoy the coded rarity of the field (Bourdieu, 1985). The enhanced cultural legitimacy accruing from these activities further augments the cultural capital of intermediaries and their subsequent capacity to influence consumers' perceptions of aesthetic taste (Wright, 2005). We have chosen fashion models as exemplars of the aestheticised styles of consumption that legitimate taste within this field.

\section{Fashion Modelling}

While Bourdieu's description of cultural intermediaries is somewhat ambiguous, his tripartite scheme of field, habitus and capital is central in illustrating the framing process. Bourdieu (1984) describes a field as a key arena in which players compete for cultural authority. Fields are heterogonous and as such, each is governed by its own rules and value system (Entwistle, 2009). Fashion is a field that fosters and celebrates an aesthetic that exists outside the parameters of conventional taste. Its esoteric nature implies that only those with unique cultural competencies can understand and appreciate its coded, avant-garde appeal (Entwistle, 2009; Mears, 2011).

Bourdieu (1990, 53) defines habitus as "systems of durable, transposable dispositions, structured structures predisposed to function as structuring structures, that is, as principles of the generation and 
structuring of practices and representations ... objectively adapted to their goals without presupposing a conscious aiming at ends or an express mastery of the operations necessary to attain them". In short, habitus refers to deeply inculcated and enduring dispositions that structure our ways of being and doing. Habitus, then, represents an individual's feel for the game with a certain field and is accompanied by the illusio or belief in the game (Crossley 2001b) such that there is a felt connection between the habitus and underlying ideologies of certain fields. This connection grants the individual greater capacity to belong to and act within this field over others: "the habitus organises how one classifies the universe of consumption objects to which one is exposed, constructing desire toward consecrated objects and disgust toward objects that are not valued in the field" (Holt 1998, 4). To act is to employ a pre-discursive, embodied mode of thinking and performance (Holt, 1998) based on a tacit way of feeling in certain situations.

Individuals deploy cultural capital within the fields to which they are bound (Holliday and Cairnie 2007). Cultural capital refers to socially rare and distinctive attributes such as tastes, skills, tacit knowledge and styles of consumption. Its embodiment "earns the respect of others through the consumption of objects that are ideationally difficult and so can only be consumed by those few who have acquired the ability to do so" (Holt 1998, 4). The effortless or seemingly natural (Bourdieu, 1984) deployment of such capital legitimates the field and those within it as special, rare and intrinsically pure.

Fashion modelling as a cultural phenomenon is inextricably linked to the rapid development of consumer culture (Entwistle and Wissinger, 2006; Entwistle and Slater, 2012). Further shifts in our understanding of brands from bundles of attributes to bundles of meaning (Levy, 1959), and concomitant movements in the nature of competition to the realm of image and aesthetics, have seen models take on an important role as progenitors of consumer desire. Their job is to effectively portray 
a future self to the consumer and become, by definition, the personification of her/his dreams (Venkatesh et al. 2010).

Fashion models represent an interesting group both theoretically and empirically, as the majority of academic attention afforded to their profession has been negative (Banister and Hogg, 2004; Gurrieri et al., 2016). Rather than figures that command significant influence in shaping cultural taste, fashion models have been theoretically framed as 'cardboard-cut-outs' (Entwistle and Wissinger, 2006; Entwistle and Mears, 2012) and considered to lack any cultural impact beyond the deleterious effects of their idealised depictions of beauty (Bordo, 1993). In contrast, Elspeth Brown $(2012,37)$ credits fashion models with the capacity to:

"transform subjective aspects of modern selfhood - gesture, appearance, presence - into immaterial commodities, adding surplus value to manufactured goods that are then purchased by wholesale buyers or retail consumers ... Models sell commodities by using their bodies to produce commercialised affect in relationship to specific goods: glamour, elegance, cool. The vehicle through which these elusive promises are made is the model's performance of a new form of sexuality, one specific to the emerging mass culture industries of the early twentieth century".

Thus the cultural capital of models augments their productive capacity, in this case to animate "a compelling story without words, using embodied expression, much as in silent motion pictures or ballet" (Parmentier and Fischer 2013, 382). Framing in this sense involves performances by fashion models that seek to materialise the fantasy elements of the fashion world (Woodward and Fisher, 2014), to produce glamour (Huopalainen, 2016), and to make it all believable, authentic, and worthy of investment:

"The fashion show ... can be seen as an ideal example of the spectacle of fashion. Yet this spectacle is materialised through the lighting, the music and the ways in which the bodies move in the clothing. If we regard light, music and movement as material ... then they all serve to make fashion 'material' in particular ways" (Woodward and Fisher 2014, 7).

For these performances to achieve their ends and to be seen as authentic they must produce a sense of verisimilitude; they must feel real. This necessitates 'performative fusion' (Alexander, 2004), an 
integration of discourse and its materialisation, of the performance and its reception (Woodward, 2006). The determination of authenticity is a product of a model's ability to "sew the disparate elements of performance back into a seamless and convincing whole", (Alexander 2004, 548). Within this context, then, performative fusion results in a perception that models effortlessly embody fashionability; they are 'in fashion'. Being in fashion is thus underpinned by cultural capital, determined by performance, and involves the embodiment of the prevailing cultural zeitgeist; "to be abreast of what has good standing, to express new tastes which are emerging in a changing world" (Blumer 1969, 282). Successful performances of fashionability also help define and legitimate cultural and aesthetic standards. Dissemination of these standards helps shape public opinion toward a "lifestyle that is then packaged and sold in the form of television shows, websites, ringtones and other branded products that consumers use to create a sense of community around the idea of fashion, in a form of pre-programmed agency that is profitable for marketers" (Wissinger 2009, 284).

In recent years, the ability to enact such performances has become publicised and monetised. The secrecy that once shrouded the modelling industry has been sacrificed as ideologies and attendant means of creating value have begun to shift. In postmodern culture, framing has attached greater emotional intensity to fashion's ideologies as cultural intermediaries have begun to infiltrate and legitimate the dreams of fashion audiences. The last decade has witnessed a slew of television shows such as The Agency, Make Me a Supermodel, America's Next Top Model, Britain \& Ireland's Next Top Model, The Janice Dickinson Modelling Agency, Project Runway, America 's Smartest Model, A Model Life, and The Face. All capitalise on the seductive air of mystique, elusiveness and romanticism that has been woven around high fashion ideologies. Such is its appeal that the Top Model franchise is now shown in 44 countries (Banks, 2007). Each show also has an online social media presence that consumers can access at any time. The mediation between culture and economy exemplified by these shows shapes our perceptions of reality and behaviour in the market. As such, consumers do not just engage with a show, but also, experience a branded lifestyle. 
While these media representations might appear superficial or frivolous to some, they do offer important insight into how we might understand the performances constitutive of cultural mediation. Their premise is a modelling competition wherein both men and women (depending on the show) vie for the chance to become a 'top model' and be signed to a prestigious modelling agency. Each week, competitors are put through a series of fashion-related challenges during which they must showcase their skills as a model. With the glamorous, branded lifestyle of high fashion as a backdrop, these challenges may constitute posing for a particular campaign, walking the runway in a designer's new creation, or exhibiting personality while interacting with the media. Although rarely acknowledged, the model is being judged on her/his performativity; on the ability to command the recognition of the viewer, to make an emotional connection and to legitimate the high fashion lifestyle as desirable and worthy of investment. Challenges that are passed successfully ensure entry to the next round and also confer aspiring models with greater cultural capital. Conversely, failure to pass the challenge illuminates a model's flaws and a disconnect with the world of high fashion. Failing contestants are eliminated and the process continues until one model remains. The winner is (s)he who has passed all challenges and earned the right to act as a cultural intermediary. In other words, successful performances and increased cultural capital confer legitimacy upon the aspiring model and endow her/him with the capacity to become an arbiter of aesthetic and cultural taste (Jones, 2013), or so it would seem. In reality the winners of these television shows rarely become established models at the elite level (Entwistle and Wissinger, 2012).

Of course, this is entertainment and its priority is not really to find the next top model. In truth, the real cultural intermediaries here are the judges, the production staff and the glamorous fashion scene in which the competition takes place. Yet while these market actors arguably never amass the productive capacity of Kate Moss, for example, the processes to which they are subjected offer an insight into the performativity of cultural intermediaries. These processes have become even more 
nuanced with the advancement of social media platforms that dissolve the distinction between public and private self (Goffman, 1978) and allow intermediaries greater opportunity to reaffirm their position as arbiters of taste (McQuarrie et al., 2012; Dolbec and Fischer, 2015). That is, we can begin to appreciate fashion models as performing bodies that work on making their unique styles of consumption appear effortless. Success temporarily affirms their place at the vanguard of aesthetic taste, described by as Parmentier and Fischer $(2007,24)$ as 'the model life': "becoming a member of a small, elite group [of models] whose bodies and personae are intensely sought after for their aesthetic singularity, and who reap culturally celebrated rewards such as money, luxurious goods, and celebrity status". To experience this life is to embody and deploy rare cultural capital such that one's effortless style of consumption will be recognised and revered by tastemakers in this field.

While consideration has been given to the consumer and the integrating practices required to authenticate their dreams, little is known about cultural intermediaries, for whom vicarious consumption of this world is insufficient. To address these issues we continue by outlining the methodology used to gain access to two mediating events within fashion culture that allow further exploration of these issues; the photo-shoot and the fashion show. Loosely following Schechner (2013) both of these events are analyzed in terms of the ritual performance, the sensibility of the model, the use of the body, and performative fusion.

\section{Methodology}

Over the countless years of visiting London, for one reason or another, I have never felt like a tourist given the multicultural nature of the city. Yet during fashion week, as I shuffle around Covent Garden, I feel more like an alien than a tourist. Given that we have all been tourists at one time, we tend to recognise the shared commonalities they embody; the leisurely stroll, the peering up at buildings, around corners or into the distance. However, I do not recognise aspects of myself in many of these people who cross the cobbles of Covent Garden. They are purposeful but leisurely, as though they have to be somewhere urgently yet, have all the time in the world to get there. My appearance, mannerisms and form contrast greatly with the majority. The way they interact with one another is somehow different. It is as though they are aware they are being watched. Each face embodies a unique quality of difference that provokes my interest, making me stare. I am truly in the minority. 
This paper employs a mix of personal introspection (Holbrook, 2006; Rod, 2011; Shankar, 2000) and observational fieldnotes (Elliott and Elliott, 2003) as a way of preparing the groundwork for the main body of this research. While deemed controversial for quite some time, Denzin $(1989,12)$ has argued, "interpretive research begins and ends with the biography and self of the researcher". Examining one's own personal and socio-cultural experience facilitates interpretation (Shankar et al. 2001). Indeed, Holbrook $(1995,29)$ describes subjective personal introspection as being the "ultimate participant observation".

While these methods were used as a supplementary tool, the primary source of data collection used for this study was narrative interviewing. Narrative inquiry adheres to the view that individuals construct their reality within the parameters set by social and cultural institutions (Shankar et al. 2001). Thus the reality of the fashion is set and defined by cultural intermediaries of varying levels of expertise, each of whom contribute to the framing process in their respective ways. This approach facilitates access to the quasi-biographical stories of participants. In accessing these experiences, the researcher seeks to understand the world from the point of view of the informant (Kvale, 1996) by attaining a first-person description of a particular domain of experience (Thompson et al. 1989) which allows for a better understanding of how the restrictive boundaries that characterise the fashion become further ingrained through the performances of cultural intermediaries and production of discourses that reaffirm the cultural rarity and mystique of this reality and those within it (Entwistle and Rocamora, 2006). Furthermore, de Man (1970, 148-149) states that experience as we understand it, "implies the necessary experience of any present as a passing experience, that makes the past irrevocable and unforgettable, because it is inseparable from any present or future". Thus, narrative interviews allow for a greater illustration of the habitus of cultural intermediaries; that is, their capacity to perform in the present based on cultural capital ingrained from past experiences. Such habitus facilitates the rarefied consumption styles of cultural intermediaries' during framing. 
As part of a larger study spanning four years, interviews were conducted with nineteen fashion models, four bookers, five designers/creative directors, three stylists, three photographers, and there was one brief conversation with a magazine editor. London Fashion Week (LFW) was identified as an important event during which players within the field would gather and implement their regimes of mediation (Cronin, 2004). However, the notion of access to this world was also an initial concern. Before entering the field and establishing a relationship with prospective participants, we considered approaching this research from a strict ethnographic perspective. Yet with access to the field granted based on fashion capital (Entwistle and Rocamora, 2006), the first author's initial rejection at four open castings and a proven lack of photogenic appeal had left little option where ethnography was concerned. Thus while not strictly ethnographic, we relied instead on personal introspection (Shankar, 2000; Holbrook, 2006) and observations (Hudson and Ozanne, 1998) during which the first author openly identified as a researcher who was writing a previously untold story on the mystique of high fashion.

For instance to gain access to LFW, the first author applied months in advance to the British Fashion Council for press accreditation which involved an application stating why the author wanted to attend LFW and importantly, how they could benefit from the author's presence. As noted, the first author identified as a researcher of the fashion industry and provided details of his $\mathrm{PhD}$ research complete with third party endorsements of this work. The Pass allowed entry to the main site of LFW where the majority of observational fieldnotes were made. To gain access to the prestigious theatre show however demanded further accreditation which the first author gleaned from existing connections within the field (i.e. social capital). The first author had a friend who was an accredited photographer in London and a regular at LFW for the past three seasons. With his help, the first author managed to secure a standing ticket that permitted entry into the hallowed fashion show. The manner in which entry was granted based on relationships demonstrated to the author the importance of social capital 
but also, the way in which an individual's capital could be bolstered through contagion; that is, by being seen with the right people, in the right places etc. Thus, identifying as a researcher proved vital. While being documented or shadowed perhaps did not bestow participants with significant fashion capital, the first author's involvement as researcher certainly legitimated their status, albeit temporarily, which in turn had a knock-on effect on the author's capital within the field.

From an analytical perspective, this paper has adopted a holistic-content/categorical perspective as outlined by Lieblich et al. (1998) in their seminal work on narrative research. Lieblich et al. (1998) categorise narrative analysis of life stories into four main categories based on two dimensions. Holistic vs. Categorical for instance refers to the unit of analysis and distinguishes whether the narrative is analysed as a whole or in sections. Content vs. Form refers to the traditional dichotomy that has always existed in terms of prioritising the meaning conveyed by a story or its structure, plot, use of metaphors etc. From these points Lieblich et al. (1998) produce four categories of narrative analysis; holistic-content, holistic-form, categorical-content and categorical-form. The holisticcontent approach focuses on an individual's entire life story and focuses on the meanings and themes conveyed within it. The meaningful themes that pervade certain aspects of the story are analysed in view of the whole story. Holistic-form examines the structure and plot of the narrative and interprets its development based on genre. Categorical-content extracts specific elements of the story into a defined category for analysis. The final category, categorical-form focuses on various linguistic and stylistic forms such as verbal utterances, metaphors etc. Given the aims of this study, a combination of holistic-content and categorical-content approaches were undertaken.

[Insert Table 1 here]

\section{The Photo Shoot}

The image can be described in many ways. But I suppose for me, it is a portal into another world insofar as the image engages you, absorbs you into that world. There is truth to be found there, in the image. 
In an economy where value circulates around aesthetics (Entwistle, 2002; Venkatesh and Meamber, 2008), the visual image provides a central conduit through which the creation of aesthetic value occurs (Schroeder, 2006). The image incorporates a "visual language that is both engaging and deceptive" for the viewer (Schroeder 2002, 115). While much work has explored the representational attributes of images (e.g., Richins, 1991; Scott, 1994; Sandikci, 1998; Ritson and Elliott, 1999; Schroeder and Borgerson, 1998; Schroeder, 2002), Featherstone (2010) introduces the idea of the affective image. Residing on a different register to beauty, the image is imbued with affective capacity that captures the attention of viewers and holds their gaze. Consumption of such images is experienced or felt through an embodied mode of thinking rather than being processed cognitively. The capacity of cultural intermediaries to channel and mobilise these pre-cognitive energies when working with photography imbues the final image with affective intensity; "something ... translated from the physical to the photographic body that is beyond conscious control of the subject ... that 'certain something' or 'charisma' that is communicated in the photograph" (Entwistle 2009, 68).

There is an air of vitality inside the shabby, abandoned warehouse. The former furniture storage facility is transformed into a set where Abel Bauer is shooting its latest fragrance campaign, We Are Alive. The scene is a dark, gritty bedroom. Off-white sheets lie in disarray. Everything here is organised to manufacture a certain ambience. Sympathetic to the rebellious nature of the brand, a loud Dubstep beat is used to help support the atmosphere. The models dance, and jaunt about the room until called upon. Sitting in the makeup chair is an impossibly beautiful woman with long, wavy, auburn hair, having her dark eye shadow reapplied.

It's a gritty, rock type of vibe. At the same time, we're communicating strong themes like love, attraction and lust. Lust is a big one ... so I'm forever dabbing the models with baby oil so it looks like they have been sweating, just to give it a bit more of a sexualised tone ... but not too much! It's a fine line [laughs]. Abi is perfect for this campaign though. I've worked with her once before, she is amazing. She just triggers passion with every move of her body and doesn't even know it. She is oblivious to how magnetic she is. 
As Abi stands proud at the foot of the bed for some individual shots, each subtle move of her body and change of facial expression captivates the room. Her magnetism, as Clare refers to it, makes it difficult to turn away. As she moves on to roll around on the bed, each suggestive pose is fleeting. Once captured by the flash of the camera, her expression is reworked quickly. She finishes the individual shots. The campaign requires some additional shots with a male model. He enters the frame of the bedroom. At this point, he appears slightly rigid. The photographer keeps barking the need for 'intense shots!' The couple now roll around on the bed but, according to Clare, it looks slightly “awkward, and lacking intimacy”. These shots aren’t working. The photographer yells: “Liam! She’s not your sister, lean in closer!"

Abi kisses Liam passionately on the lips. This draws a gasp from onlookers and with that a surge of confidence shoots through Liam as he removes Abi's vest top. They writhe around on the sheets, holding, grabbing and kissing each other while always remaining within the frame of the shot. The photographer falls silent so as not to interrupt their flow. There is a definite change in energy. The atmosphere is one of intense intimacy during which both models appear liberated, confident and lustful. After ten minutes of constant shooting, the models begin to slow down. They laugh hysterically when they remember the audience standing about on set. Rapturous applause echoes around the warehouse.

When you add that certain something that a great model brings ... it's not just a picture anymore ... it's as if it is talking back to you. I always equate it to falling in love [laughs]. I've been married for twelve years, but even that ... how do you explain falling in love to someone who has never been? Like, you can't make yourself fall in love can you? It just happens. Even if you have a string of relationships beforehand, you tip along not really feeling anything too major and then all of a sudden you meet the one, and you feel completely different. Your entire world is upended. In that moment, you don't feel the same as you did in the minute previous. And ... without sounding incredibly pretentious or self-indulgent ... when it all comes together in a shoot, that's what it's like ... it's overwhelming. You fall in love a little bit ... well not a little bit, a lot! Don't tell my husband [laughs]. But you can't order that you know? It just has to happen.

Clare [Make-up Artist, 27] 
The explosive and charismatic energy discharged by the pair is captivating. The world around stands still. I am riveted. I did not necessarily want the product. I wanted those images that were unfolding before me, being captured in print. The photographer jokes that the toughest job he has is to choose those images that Abel Bauer could use and that wouldn't be banned. While packing up, I notice both models shake hands: "It was lovely working with you, bye," Abi says as she skips across the street to where her boyfriend is waiting.

This observation is evocative of the idea that the cultural intermediary's habitus (i.e. taste, lifestyle and cultural capital) is not only necessary for the production of cultural products, but also influences their productive capacity in certain situations. The fashion model must possess an embodied knowledge or way of feeling (Merleau-Ponty, 1962) during the shoot that facilitates their connection with the camera and the networks of human and non-human actors in the room: "Frequently, models at this level are not given direction; instead they are called on to channel the mood and energy present in the room, to open themselves to the possibilities of the moment, to collaborate with the team assembled in the hope of capturing something unexpected, something that moves beyond the norm, toward the unknown", (Wissinger, 2007: 260). As suggested by Clare, such a connection allows the photographer to capture a moment that will affect viewers, confound their sense of logic, and invoke a distancing from the immediacy of everyday life.

\section{The Fashion Show}

The fashion show is a cornerstone of fashion. The reason it is still around is the same reason anyone still goes to the theatre, cinema or a football match ... to be entertained ... to feel something. Fashion is much more than clothing. It's ... art. It's a complete spectacle! That's where Alexander McQueen was amazing ... the shows. That guy was a genius at creating a spectacle with fashion. Being at his show felt like being at the centre of the world.

Adele (Theatre Set-Designer, 43) 
The fashion show is a biannual mediation ritual, a stage upon which cultural intermediaries mobilise embodied styles of consumption designed to paralyse objectivity and rationality while authorising and glorifying an alternative hyperreality (Rocamora, 2001; Rocamora, 2002a). It is "constituted by a variety of expressions, non-verbal and verbal actions, movements, meanings and doings generated across different spaces, with powerful audiences, producers and multiple contextual conventions involved", (Huopalainen 2015, 831). Rather than establish community, the fashion show seeks to generate awe by appropriating avant-garde ideologies from art and magic (Dion and Arnould 2011; Joy et al. 2014). Entwistle and Rocamora (2006) observe that visibility at shows during London Fashion Week is central to affirming one's belonging within the field where competition for cultural legitimacy is rife. At these "ceremonies of consecration" (Bourdieu 2000), the seating plan is arranged so that those with the greatest cultural capital are allocated a view from the front row. Seats are not bought. Seats are earned by becoming a cultural authority. Further, the value placed on aesthetics is such that most fashion shows are in fact produced at a loss for the brand (Entwistle and Rocamora 2006). For example, fashion brand Dolce \& Gabbana reportedly sells $75 \%$ of their new clothing line before it is ever showcased on the runway (Mears 2011). The fashion show, then, is a purely theatrical ritual designed to reproduce and legitimate a belief in the value of the field as special and ethereal (Bourdieu, 1993).

I sit clutching my press badge as my eyes struggle to adjust to the complete darkness. I don't want to move, afraid I might brush against the stranger sitting either side of me. I am paralysed by a mix of vulnerability and expectation. With my eyes out of commission, my other senses kick into gear. My nose catches the earthy notes of frankincense in the air while my ears pick up the whispered premonitions of what is to come. A flame from an old Victorian gas lamp flickers outside the Ten Bells pub, shedding light on a cobbled runway. The runway is flanked on either side by dank shadows and it extends to a cold, ominous archway shrouded in mist. As I begin to sensitise myself to the surroundings, a beautiful woman with tousled ruby red hair and pale white skin slowly meanders 
down the cobbles. Poppies are pinned to her shabby, emerald green evening dress and she clutches a withered bouquet of daisies. She sings wistfully ...

Underneath the gas light's glitter,

Stands a fragile little girl;

Heedless of the night winds bitter,

As they round about her whirl.

While the thousands pass unheeding

In the evening's waning hours;

Still she cries with tearful pleading,

Won't you buy my pretty flowers?

The beautiful fragility of the moment is broken by the sound of footsteps from the shadows that appear to lure the girl in. "Why hello there ... haven't seen you around these parts before ..." she says in a distinct East London accent. With that she disappears into the shadows. "Oh my, what a beautiful bouquet of flowers! Are those for me?" I could hear her take the aroma in deep through her nose before exhaling with a pleasant sigh. As she did so, I noticed the steel blade produced from behind her suitor's cloak as it glimmers in the light of the gas lamp. Her screams echo through the room as a bouquet of daisies are cast onto the cobbles. The room is plunged into darkness once more. More footsteps. “Ahhh!!” screams a frightened young boy. "He’s struck again! The Ripper! The Ripper!”

The runway bursts into light. Pale-skinned models, dark shadows under their eyes, stalk the runway. They don't move like human beings, but like beasts. I stare, captivated by one model in particular. Clad in a traditional Victorian mourning dress, modified slightly with a high collar and ruffled cuffs, she meanders toward the Ten Bells where she pins a letter entitled "From Hell" to the door. Her eyes seem to prophesise the death of the ordinary. She conjures the most hedonistic images in my mind. And so it goes for a further nine minutes. At its tamest, I experience an emotional upheaval. In truth, it is a violent disruption of the mundane fabric of my everyday life.

Henrik: People say we are just clothes hangers which is absolutely rubbish. If that was the case, just put the clothes on a hanger, you know? Leave them off on a conveyor belt down the runway, see what the reaction is like. It really annoys me when people think they know about what I do, when in reality they haven't a clue ... I went to a haunted house when I was 8 years old at a carnival in Brighton, fairly shoddy job. It was one of 
those ghost trains you know? Sat in with my sister and was going along nice and slowly. There was a lot of gothic, monstrous type imagery around; it was eerie but not really scary. But it was always that moment at the very end, the crescendo when the hand used to touch your shoulder. It always made me jump out of my skin! [laughs] It was probably just a guy in the dark or even a wind machine but I was convinced that there was a monster behind me attempting to drag me away ... that was the scariest part, it always left my heart pounding.

Simon: Are you saying we're monsters? [laughs]

Henrik: Well no, but like, the whole atmosphere is built up, but it's only when someone jumps out of the dark that you feel ... alive with fright you know? Your emotions are heightened by the imagery and all that ... but it's that touch ... tips you over the edge and makes the whole experience memorable.

Henrik makes an interesting comparison between the fashion show and a theme park ride in that both are theatrical orchestrations and performances designed to impinge upon the consumer's sense of being. In his example, the intensity of the ghost train experience, animated by human and non-human actors, overrides his sense of logic and provokes his belief in an imaginative construction. The experience leaves him feeling terrified, his heart pounding.

The model's runway walk is an equivalent phenomenon in that the embodied mobilisation of persona and attitude in the walk helps frame the field of fashion as simultaneously otherworldly and something to believe in: "By dynamically interacting with others through times and spaces, bodies perform both scripted and improvised movements that disrupt, affect and re-organise bodies in a variety of material and temporal ways", (Huopalainen 2015, 830).

A model with a great walk is just something to behold. It exudes an energy that commands this hold over you ... where you are just mesmerised by the effortlessness of it all. Obviously modelling is predominantly non-verbal but when a model walks the runway, they communicate more than words can ... they are showing us their personality, their attitude ... that they are strong, confident, in control ... fashionable. That's why I hate it when I hear of modelling agencies teaching their models how to walk in this generic, preconditioned way. It completely kills any creativity or personality that the model might develop. How can you teach personality? I mean, obviously there are similarities to every walk but it's just that little change here or there that makes a model stand out from the rest. Like during New York Fashion Week, male models in particular have to walk quicker than usual. It's a more fast-paced jaunt down the runway because the theme of the show will be New York based so ... hectic, busy, chaos etc. Paris on the other hand is a slower, withdrawn, more fluid walk where the model looks like they are floating. The New York style for instance just fills you with energy; it evokes such vibrancy and 
aliveness. The Paris one is very ethereal ... like I say, they just float down the runway as though they have a pair of angel wings strapped to their backs.

$$
\text { Jonny [Casting Director, 40] }
$$

That the walk is "something to behold" affords cultural capital to both the model and also those that can appreciate its mastery. The walk is a fully embodied stylistic performance of aesthetic taste. The energetic flows it produces hold one's imagination.

Robert: My designs are not brash or loud. They are subtle, and kind of shy ... so the walk doesn't need to be this macho, confident, chest out look at me arrogant strut, I hate that. That's not who I want modelling my collection. And that's why I work with Noel here, because he embodies the spirit of my collection so well, he is effortlessly seductive. In fact in many ways, I would say he is responsible for my more recent collections ... I wanted my designs to just have this subtle, shy, elusive, dreamlike feel to them. And for years I was trying to capture this but anytime I put them on a model, it just didn't fit ... the clothes didn't speak to me on their bodies like I knew they could in my imagination. They had no personality, no soul. But Noel just seemed to get it. He could wear them in a way that captured the essence of what I was trying to communicate. I remember the day I met him, it was at a fashion show where a bunch of friends and I were showcasing our batches of ... not cheaper stuff but stuff that wasn't necessarily right for fashion week ... can I say leftovers?? [laughs] One of my models pulled out and I was one short so I asked some friends from the agency to send a guy over. He was like a frightened fawn, all skinny, hair covering his face, unsure of himself. He shuffled in with his head looking at his feet, shoulders hunched and hands glued to his pockets. It had already been a long day and when I saw him drag himself across the floor I thought: "Oh for Christ's sake, what have they sent me this waste of time and space for? Is this a joke?" Because backstage at a fashion show is the most hectic hour you'll ever have ... there are people running around shouting, making sure everything is going to plan. And this guy was the complete opposite, just came in cool as a breeze. I was stressed so I think I snapped at him when I saw him just doing nothing: "Can you walk!?" He said: "Yeah I walked here". I immediately thought the guy was simple or something but I just shooed him off to wardrobe to get him ready. He took his shirt off. He was this skinny waif of a guy, smaller than the model who pulled out so the jumpers hung on him more. I thought this is going to be an absolute disaster! I was considering not letting him out there when I saw him, the jeans were loose, the hair was a mess because he didn't have time for styling but I had to let him go out or else the numbers would have been uneven. So I remember seeing them all in a line waiting to go out there. They all had their back to me [laughs] and Noel was the only one who was kind of fidgeting, pulling at the clothes you know? [laughs] I was like: "What the hell! Are you actually stretching my clothes?" [laughs]

Noel: I was just trying to get comfortable! [laughs]

Robert: Before it was his turn to walk I had to go around to stage-side just to see how bad it was going to be. I had my eyes half covered and was peeping through my hands. But when he came out I couldn't believe it. He was just effortless. He didn't walk like a professional model but that is exactly what my collection needed! He kind of shuffled down the runway, my designs were hanging from his thin frame, the jumper stretched so that his collarbone was on show, the sleeves hung completely covering his hands. The 
way his body moved ... he just embodied this effortless charisma ... he had his hands in his pockets, shoulders hunched like a child sulking off to his room. He later told me that he only had his hands in his pockets to hold up his trousers that were coming loose, but it worked! He was so enchanting ... just floated down the runway. He gave the designs some attitude, some character that they had been lacking.

Noel: Well I loved the fact that they weren't the favourite collection, that they were moments away from being thrown in the bin. Already that gave them some character in my mind, like nobody wanted them, it made them different. So they had to be worn like that, like some sort of cast-off fashion. I've always been pretty attuned to how to wear something to its best advantage ever since I was a kid. Because I grew up in a pretty big family. There were seven of us, four boys and three girls. We didn't have a whole lot of money so hand me downs were the order of the day. And this is ... you're probably thinking this happened around 4 or 5, this was taking place up until 16 and 17. [laughs] So not so long ago! And there would always be fights over who got to wear what on a certain day and that kind of thing. And of course brothers being brothers ... if there was a certain day I wanted to wear a particular t-shirt, my other brothers would wear it or hide it or something like that so I just had to wear the next best thing. I remember even sharing clothes with my sisters now that I think of it [laughs]. In hindsight it prepared me well for a career in modelling because I learned how to wear something well ... you know? Even if it wasn't my first choice, I had to put up with it and wear it. I guess I just learned how to manipulate clothes.

This lengthy passage conveys important insights into framing, but also how the sensibility of the model allows for a performativity that charges a branded collection with cultural legitimacy by virtue of how the clothing is worn. Robert describes his experience of observing Noel walk as epiphanic. He knows that his collection needed someone with an understated charisma to convey the qualities of subtlety, shyness, elusiveness etc. The moment during which he becomes enchanted by Noel's productive capacity is a conversion experience for Robert (Kozinets and Handelman, 2004). Noel's style of consumption communicates distinguishes him from others that had previously been modelling the collection. The fact that Noel's walk is "inhibited" by hitching up his trousers further emphasises the natural predisposition or habitus of his rare affective persona.

Similarly, we interpret clues as to Noel's unique productive capacity based on his romanticising of the collection. For example, that they "weren't the favourite collection" and were "moments away from being thrown in the bin" endows these garments with a narrative that pitches it as ripe for subsequent transformation and triumph. Noel also appears to possess a tacit understanding of how to 
wear these creations in such a way that facilitates the mobilisation of attachment to the product line. Noel's seemingly effortless capacity to evoke charisma, while appearing innate, derives from the cultural/emotional capital accrued from sediments of past experiences (Merleau-Ponty 1962; Bourdieu 1984), which he also documents. For example, he romanticises his experiences living in a big family that did not have much money. We interpret these experiences as central to conferring him with the cultural competency to manipulate the character of clothing and transform it into something more. This particular line of clothing was not thrown out, but instead, transformed into a new fall/winter collection.

On occasion, there are instances where the fit between a model's tacit, embodied style of performance and the cultural milieu break down (Crossley, 2001a). Performance once disguised as magical and effortless becomes exposed, and, consequently, the illusion is revealed. That is, the myth of the 'ugly duckling' (Parmentier and Fischer, 2011) (the idea that the model is an aesthetically unique, unconventional beauty who innately possesses the magical capacity to bewitch onlookers) is exposed as a visibly laboured process disrupts the seamless flow of affective energy and removes the possibility for performative fusion. Such instances invoke different, negative emotions (embarrassment, awkwardness etc.) in relational bodies. The cultural legitimacy of intermediaries is compromised as a result and they are proven to be mortal after all. The ethereality of the consumption experience is undermined as it becomes contaminated with adverse intensities:

Adele: Oh my days! Don't even say the F word! [laughs] Falling is the worst thing that can happen to a model on the runway. It can end your career in an instant. It has for some. Last year at London Fashion Week there was a girl walking the runway in a floor-length dress and she caught her shoe in it, tripped and fell over. It was horrific. I think she continued on and walked back. But as soon as she went backstage and took the dress off, she was done.

Fiona: Yeah, models are supposed to be mesmerising. So a model that floats down the runway and effortlessly wears the designs ... you can't take your eyes off them. They captivate your attention and they lull you into their fantasy. So now you can't help but imagine what you would look like in those clothes, how they will transform you. With the brand behind you, now you'll get that job you wanted, that girl you like will suddenly notice you, attractive people might glance at you on the street etc ... Life as it was intended to be. But falling ... that's just ... being jolted awake from the nicest dream and realising 
that that's exactly what it was, a dream. After a fall, the model is seen as a pretender almost and the whole fantasy of this perfect life you imagined is shattered. The repercussions on the brand could be catastrophic.

When performed fluidly, an effortless walk enchants the consumer and legitimates the experience as transcendent and pure. Conversely, the suggestion or confirmation of effort made by falling demonstrates mortality and subsequently shatters the cultural legitimacy of fashion and the viewer's desire and ability to vicariously consume this life is hampered. Thus the performative vagaries of fashion models can either bewitch viewers into believing in, and desiring this life, or alternatively, can affirm the ordinariness and subsequent disenchantment felt in their present, mundane reality.

\section{Discussion}

This work has presented fashion as a field of restricted production (Bourdieu, 1984) that demands unique cultural competencies of its members if they are to participate. Value in the field is aesthetic and derives from framing the experiential fantasy of fashion as intrinsically pure rather than based on corporate motives. A belief in the aesthetic value of fashion is created and disseminated by cultural intermediaries through their performances in mediating events such as photo-shoots and fashion shows. During these events, models frame the world of fashion through aesthetically stylised and esoteric performances that disguise the effort behind them (Huopalainen, 2016).

Bourdieu $(1984,365)$ notes that intermediaries "sell so well because they believe in what they sell". Suspension of disbelief is thus an important condition for the development of cultural capital and perpetuation of habitus among cultural intermediaries (as ideal consumers). Also referred to as selfdeception or self-mystification (Bourdieu, 1998; Dillon, 2001; Schroeder, 2002), cultural mediation of the illusio is central to the legitimation of fashion as an aspirational dream. Intermediaries' misrecognition of their labour through assimilation practices (Holt, 1995) frames the world of fashion as a magical, ethereal and spiritual existence. This research interprets moments of illusio during the photo shoot where both fashion models (eventually) draw on their cultural capital to animate an 
intense, passionate moment of intimacy that would be captured in a momentary shot. Similarly, illusio is embodied in the unique embodied performances of models (i.e. the walk) as well as through their discursive reflections on the process (exhibited by the Robert and Noel narrative). We also offer a glimpse here of moments where embodied breaches (Thrift, 2010) in performance serve to unmask the illusio. For example, the detrimental consequence attached to falling on the runway is to expose the labour and effort required to appear effortless (Huopalainen, 2016).

These events take place in a field where the process of cultural mediation is becoming increasingly ambivalent. It appears we are all cultural intermediaries now, although to varying degrees. For instance, the cultural commodity of fashion is "produced by and for producers" (Rocamora 2002a, 344). The ritualistic and aestheticised machinations of the field are mobilised to affect those within the field whereupon they become willing participants in their own seduction (Wernick, 1991; Deighton and Grayson, 1995; Hoch, 2002; Rokka and Canniford, 2016). Through suspension of disbelief, intermediaries with inadequate cultural capital can participate in the fantasy through attempted mimicry of the consumption styles of more expert intermediaries. Their inevitable failure is an integral and necessary part of the framing process as it condemns them to exist on the periphery of the field (Parmentier and Fischer, 2007; 2013; 2015) thus perpetuating the legitimacy of the field as special, mysterious and inhabited by only a chosen few.

\section{Conclusion}

This research set out to add greater clarity to what cultural intermediaries do when they mediate between economy and culture. Considering intermediaries as contextualised marketplace actors (Smith-Maguire and Matthews, 2012), our work adopts fashion as a field within which cultural mediation is critical given that aesthetic value and cultural legitimacy supersede a drive for economic gain. For their capacity to personify our dream selves (Venkatesh and Meamber, 2010; Atik and Firat, 2013), this work focuses on fashion models. As the fashion field is constructed around beliefs as to 
what constitutes value, the empirical data demonstrates how fashion models' embody the illusio of the field and authenticate the values, meanings and identities inherent in it through aestheticised and rarefied styles of performance. These activities seduce other market actors and engender a willing suspension of disbelief that in turn mobilises affective intensities resulting in perceptions of legitimacy. The assimilation practices (Holt, 1995) expertly performed by cultural intermediaries affect other intermediaries through contagion thus provoking imitation, which serves to perpetuate the cultural legitimacy of the field as one of restricted production.

\section{References}

Alexander, J. (2004), "Social performance between ritual and strategy", Sociological Theory, Vol. 22 No. 4, pp. 527-573.

Arnould, E. J. (2004), "Beyond the sacred-profane dichotomy in consumer research", Advances in Consumer Research, Vol. 31, pp. 52-53.

Arnould, E. J., and Price, L.L. (1993), "River Magic: Extraordinary Experience and the Extended Service Encounter", Journal of Consumer Research, Vol. 20 No.1, pp.24-45.

Atik, D., and Frrat, A. F. (2013), "Fashion creation and diffusion: The institution of marketing", Journal of Marketing Management, Vol. 29 No.7-8, pp. 836-860.

Banister, E. and Hogg, M. (2004), "Negative symbolic consumption and consumers' drive for selfesteem: The case of the fashion industry", European Journal of Marketing, Vol. 38 No. 7, pp. 850 868.

Banks, T. (2007), www.TyraBanks.com [accessed 10/04/2014]

Beck, U. (2003), "Introduction: Cultural work, cultural workplace - Looking at the cultural industries", in Beck, A. (ed.) Cultural Work: Understanding the Cultural Industries, New York, NY: Routledge, pp. 1-12.

Belk, R., and Costa, J. (1998), "The mountain man myth: A contemporary consuming fantasy", Journal of Consumer Research, Vol. 25 No.3, pp. 218-240.

Belk, R., Ger, G. and Askegaard, S. (2003), "The fire of desire: A multi-sited inquiry into consumer passion”, Journal of Consumer Research, Vol. 30 No. 3, pp. 326-351.

Blumer, H. (1969), "Fashion: From class differentiation to collective selection", The Sociological Quarterly, Vol.10 No. 3, pp. 275-291.

Bordo, S. (1993), Unbearable Weight: Feminism, Western Culture, and the Body, Berkeley, CA: University of California Press.

Bourdieu, P. (1984), Distinction: A Social Critique on the Judgement of Taste, New York, NY: Routledge \& Kegan Paul Ltd. 
Bourdieu, P. (1985), “The market of symbolic goods”, Poetics, Vol. 14 No. 1-2, pp. 13-44.

Bourdieu, P. (1990), In Other Words: Essays Towards a Reflexive Sociology, Stanford, CA: Stanford University Press.

Bourdieu, P. (1993), Sociology in Question, London: Sage.

Bourdieu, P. (1995), "Sur les rapports entre la sociologie et l'histoire en Allemagne et en France", Actes de la Recherche en Sciences Sociales, Vol. 106 No.1, pp. 108-22.

Brown, E. (2012), "From artist's model to 'natural girl': Containing sexuality in early TwentiethCentury modelling", in Entwistle, J., and Wissinger, E. (eds.) Fashioning Models: Image, Text and Industry, London: Bloomsbury, pp. 37-55.

Campbell, C. (1987), The Romantic Ethic and the Spirit of Modern Consumerism, Oxford: Blackwell.

Cronin, A. (2004), "Regimes of mediation: Advertising practitioners as cultural intermediaries?" Consumption, Markets and Culture, Vol. 7 No. 4, pp. 349-69.

Crossley, N. (2001a), The Social Body: Habit, Identity and Desire, London: Sage.

Crossley, N. (2001b), "Embodiment and social structure: A response to Howson and Inglis", The Sociological Review, Vol. 49 No. 3, pp. 318-326.

De Man, P. (1970), "Literary History and Literary Modernity", American Academy of Arts \& Sciences, Vol. 99 No.2, pp. 384-404.

Deighton, J., and Grayson, K. (1995), "Marketing and Seduction: Building Exchange Relationships by Managing Social Consensus”, Journal of Consumer Research, Vol. 21 No.4, pp. 660-676.

Dillon, M. (2001), "Pierre Bourdieu, religion, and cultural production", Cultural Studies - Critical Methodologies, Vol.1 No. 4, pp. 411-429.

Dion, D., and Arnould, E. (2011), "Retail luxury strategy: Assembling charisma through art and magic", Journal of Retailing, Vol. 87 No. 4, pp. 502-520.

Dolbec, P. and Fischer, E. (2015), "Refashioning a field? Connected consumers and institutional dynamics in markets", Journal of Consumer Research, Vol. 41 No. 6, pp. 1447-1468.

Elliott, R. and Jankel-Elliott, N. (2003), "Using ethnography in strategic consumer research", Qualitative Market Research: An International Journal, Vol. 6 No. 4, pp. 215-223.

Entwistle, J. (2002), "The aesthetic economy The production of value in the field of fashion modelling", Journal of Consumer Culture, Vol. 2 No.3, pp. 317-339.

Entwistle, J. (2006), “The Cultural Economy of Fashion Buying”, Current Sociology, Vol. 54 No.5, pp. 704-724.

Entwistle, J. (2009), The Aesthetic Economy of Fashion: Markets and Value in Clothing and Modelling, New York, NY: Berg.

Entwistle, J. and Mears, A. (2012), "Gender on display: Performativity in fashion modelling”, Cultural Sociology, Vol. 7 No.3, pp. 320-335. 
Entwistle, J. and Slater, D. (2012), "Models as brands: Critical thinking about bodies and images", in: Entwistle, J., and Wissinger, E. (eds.) Fashioning Models: Image, Text and Industry, London: Bloomsbury, pp. 15-36.

Entwistle, J. and Wissinger, E. (2006), "Keeping up appearances: Aesthetic labour in the fashion modelling industries of London and New York", The Sociological Review, Vol. 54 No. 4, pp. 774794.

Entwistle, J., and Rocamora, A. (2006), "The field of fashion materialised: A study of London Fashion Week", Sociology, Vol. 40 No. 4, pp. 735-751.

Entwistle, J., and Wissinger, E. (2012), Fashioning Models: Image, Text and Industry, London: Bloomsbury.

Featherstone, M. (2010), "Body, image and affect in consumer culture", Body \& Society, Vol. 16 No.1, pp. 193-221.

Firat, A.F., and Venkatesh, A. (1995), "Liberatory Postmodernism and the Reenchantment of Consumption”, Journal of Consumer Research, Vol. 22 No.3, pp. 239-267.

Goulding, C., and Saren, M. (2009), "Performing identity: an analysis of gender expressions at the Whitby goth festival”, Consumption, Markets and Culture, Vol. 12 No.1, pp. 27-46.

Gurrieri, L., Brace-Govan, J. and Cherrier, H. (2016), "Controversial advertising: Transgressing the taboo of gender-based violence", European Journal of Marketing, Vol. 50 No. 7/8, pp. 1448-1469.

Holbrook, M. (1995), Consumer research: Introspective essays on the study of consumption. Thousand Oaks, CA: Sage Publications.

Holbrook, M. (2006) "Consumption experience, customer value, and subjective personal introspection: An illustrative photographic essay", Journal of Business Research, Vol. 59 No. 6, pp. 714-725.

Holliday, R. and Cairnie, A. (2007), “Man made plastic: Investigating men's consumption of aesthetic surgery”, Journal of Consumer Culture, Vol. 7 No. 1, pp.57-78.

Holt, D. (1995), "How consumers consume: A typology of consumption practices", Journal of Consumer Research, Vol. 22 No. 1, pp. 1-16.

Holt, D. (1998), “Does cultural capital structure American consumption?”, Journal of Consumer Research, Vol. 25 No. 1, pp. 1-25.

Huopalainen, A. (2015), "Who moves? Analyzing fashion show organising through microinteractions of bodily movement", Ephemera, Vol. 15 No. 4, pp. 825-846.

Huopalainen, A. (2016), "Manipulating surface and producing 'effortless' elegance: Analysing the social organisation of glamour", Culture and Organization, pp. 1-21.

James, Y., Handelman, J. and Taylor, S. (2011), "Magical thinking and consumer coping", Journal of Consumer Research, Vol. 38 No. 4, pp. 632-649.

Jenkins, R., Nixon, E. and Molesworth, M. (2011), "Just normal and homely: The presence, absence and othering of consumer culture in everyday imagining", Journal of Consumer Culture, Vol. 11 No. 
Jones, J. (2013), Models as cultural intermediaries: A discourse analysis of the program Britain and Ireland's Next Top Model, Unpublished Thesis (M.A.), University of Manitoba.

Joy, A., Wang, J., Chan, T.-S., Sherry, J. and Cui, G. (2014), "M(Art) worlds: Consumer perceptions of how luxury brand stores become art institutions", Journal of Retailing, Vol. 90 No.3, pp.347-364.

Kozinets, R., and Handelman, J. (2004), "Adversaries of consumption: Consumer movements, activism, and ideology", Journal of Consumer Research, Vol. 31 No. 3, pp. 691-704.

Kvale, S. (1996), InterViews, Thousand Oaks, CA: Sage.

Lanier, C., and Rader, C. (2015), “Consumption experience: An expanded view”, Marketing Theory, Vol. 15 No. 4, pp. 1-22.

Levy, S. (1959), “Symbols for sale”, Harvard Business Review, Vol. 37 No.4, pp.117-124.

Lieblich, A., Tuval- Mashiach, R. and Zilber, T. (1998), Narrative analysis: Reading, analysis and interpretation, New Dheli, India: Sage Publications.

Maes, H. (2011), "Drawing the line: Art versus pornography”, Philosophy Compass, Vol. 6 No. 6 , pp. 385-397.

McCracken, G. (1986), "Culture and consumption: A theoretical account of the structure and movement of the cultural meaning of consumer goods", Journal of Consumer Research, Vol. 13 No.1, pp. 71-84.

McQuarrie, E., Miller, J. and Phillips, B. (2012), "The megaphone effect: Taste and audience in fashion blogging", Journal of Consumer Research, Vol. 40 No. 1, pp. 136-158.

Mears, A. (2010), "Size zero high-end ethic: Cultural production and the reproduction of culture in fashion modelling", Poetics, Vol. 38 No. 1, pp. 21-46.

Mears, A. (2011), Pricing Beauty: The Making of a Fashion Model, Berkeley, CA: University of California Press.

Merleau-Ponty, M. (1962/1981), The Phenomenology of Perception, London: Routledge.

Molloy M. and Larner W. (2010), "Who needs cultural intermediaries indeed? Gendered networks in the designer fashion industry", Journal of Cultural Economy, Vol. 3 No. 3, pp. 361-377.

Murray, J. B. (2002), “The Politics of Consumption: A Re-Inquiry on Thompson and Haytko's (1997) 'Speaking of Fashion"”, Journal of Consumer Research, Vol. 29 No.3, pp. 427-440.

Neff, G., Wissinger, E. and Zukin, S. (2005), "Entrepreneurial labour among cultural producers: "Cool" jobs in "hot" industries", Social Semiotics, Vol. 15 No.3, pp. 307-334.

Negus, K. (2002), "The work of cultural intermediaries and the enduring distance between production and consumption", Cultural Studies, Vol. 16 No. 4, pp. 501-15.

Nixon, S., and DuGay, P. (2002), "Who needs cultural intermediaries?", Cultural Studies, Vol. 16 No. 4, pp. 495-500. 
O'Shaughnessy, J. and O'Shaughnessy, N. (2002), "Marketing, the consumer society and hedonism", European Journal of Marketing, Vol. 36 No. 5/6, pp. 524 - 547.

Parmentier, M. and Fischer, E. (2015), "Things fall apart: The dynamics of brand audience dissipation”, Journal of Consumer Research, Vol. 41 No.5, pp. 1228-1251.

Parmentier, M., and Fischer, E. (2007), "Working to Consume the Model Life: Consumer Agency Under Scarcity", Research in Consumer Behaviour, Vol. 11 No.1, pp. 23-39.

Parmentier, M., Fischer, E., and Reuber, A. (2013), "Positioning person brands in established organisational fields", Journal of the Academy of Marketing Science, Vol. 41 No.3, pp. 373-387.

Preece, C. Kerrigan, F. and O'Reilly, D. (2016), "Framing the work: the composition of value in the visual arts", European Journal of Marketing, Vol. 50 No. 7/8, pp. 1377-1398.

Richins, M. (1991), "Social Comparison and the Idealised Images of Advertising", Journal of Consumer Research, Vol. 18 No.1, pp. 71-83.

Ritson, M. and Elliott, R. (1999), "The social uses of advertising: an ethnographic study", Journal of Consumer Research, Vol. 26 No. 3, pp. 260-277.

Rocamora, A. (2001) "High Fashion and Pop Fashion: The Symbolic Production of Fashion in Le Monde and The Guardian", Fashion Theory, 5(2), 123-142.

Rocamora, A. (2002a), "Fields of fashion: Critical insights into Bourdieu's sociology of culture", Journal of Consumer Culture, Vol. 2 No. 3, pp. 341-362.

Rocamora, A. (2002b), "Le Monde's discours de mode: creating the créateurs", French Cultural Studies, Vol. 13 No. 37, pp. 83-98.

Rod, M. (2011), "Subjective personal introspection in action-oriented research", Qualitative Research in Organizations and Management: An International Journal, Vol. 6 No. 1, pp. 6-25.

Rokka, J. and Canniford, R. (2016), "Heterotopian selfies: how social media destabilises brand assemblages", European Journal of Marketing, Vol. 50 No. 9/10, pp. 1789-1813.

Sandikci, O. (1998), "Images of women in advertising: A critical-cultural perspective", European Advances in Consumer Research, Vol. 3, pp. 76-81.

Schechner, R. (2013), Performance Studies: An Introduction, London: Routledge.

Schroeder, J. (2002), Visual Consumption, Oxford: Routledge.

Schroeder, J. and Borgerson, J. (1998), "Marketing images of gender: A visual analysis", Consumption, Markets and Culture, Vol. 2 No. 2, pp. 161-201.

Scott, L. (1994), "Images in advertising: The need for a theory of visual rhetoric", Journal of Consumer Research, Vol. 21 No. 2, pp. 252-273.

Shankar, A. (2000), "Lost in music? Subjective personal introspection and popular music consumption", Qualitative Market Research: An International Journal, Vol. 3 No. 1, pp. 27-37.

Shankar, A., Whittaker, J. and Fitchett, J. (2006), Heaven knows I'm miserable now, Marketing 
Theory, Vol. 6 No.4, pp. 485-505.

Smith-Maguire, J. and Matthews, J. (2012), “Are we all cultural intermediaries now? An introduction to cultural intermediaries in context”, European Journal of Cultural Studies, Vol. 15 No.5, pp. 551562.

Thompson, C. and Haytko, D. (1997), "Speaking of fashion: Consumers' Self- Conceptions, Body Images, and Self- Care Practices”, Journal of Consumer Research, Vol. 24 No. 1, pp. 139-153.

Thompson, C. J., Locander, W. B., and Pollio, H. R. (1989), "Putting consumer experience back into consumer research: the philosophy and method of existential- phenomenology", Journal of Consumer Research, Vol. 16 No.2, pp. 133-146.

Thrift, N. (2010), "Understanding the material practices of glamour", in Gregg, M., and Seigworth, G. (eds.), The Affect Theory Reader, London: Duke University Press, pp. 289- 296.

Venkatesh, A. and Meamber, L. (2006), "Arts and aesthetics: Marketing and cultural production", Marketing Theory, Vol. 6 No.1, pp. 11-39.

Venkatesh, A., and Meamber, L. A. (2008), "The aesthetics of consumption and the consumer as an aesthetic subject”, Consumption, Markets and Culture, Vol. 11 No.1, pp. 45-70.

Venkatesh, A., Joy, A., Sherry J., and Deschenes, J. (2010), "The aesthetics of luxury fashion, body and identify formation", Journal of Consumer Psychology, Vol. 20 No. 4, pp. 459- 470.

Wagner, J. (1999), “Aesthetic value: Beauty and art in fashion”, in Holbrook, M.B. (ed.) Consumer Value: A Framework for Analysis and Research, London: Routledge, pp.126-146.

Wernick, A. (1991), Promotional Culture: Advertising, Ideology and Symbolic Expression, London: Sage Publications.

Wissinger, E. (2007), "Modelling a way of life: Immaterial and affective labour in the fashion modelling industry", Ephemera: Theory and Politics in Organization, Vol. 7 No. 1, pp. 250-269.

Wissinger, E. (2009), "Modelling consumption: Fashion modelling work in contemporary society", Journal of Consumer Culture, Vol. 9 No.2, pp. 273-296.

Woodward, I. (2006), "Investigating consumption anxiety thesis: aesthetic choice, narrativisation and social performance”, The Sociological Review, Vol. 54 No. 2, pp. 263-282.

Woodward, S. and Fisher, T. (2014), "Fashioning through materials: Material culture, materiality and processes of materialization”, Critical Studies in Fashion \& Beauty, Vol. 5 No. 1, pp. 3-23.

Wright, D. (2005), "Mediating production and consumption: Cultural capital and cultural workers", The British Journal of Sociology, Vol. 56 No. 1, pp. 105.

\section{Table 1. Informant's Profiles}

'Clare', 27 
Clare has worked in the fashion industry for 5 years having attended a makeup artistry school and building a portfolio that began to win her some renown locally. Having worked in theatre during the early part of her career, she developed relationships with various significant authorities in these cultural industries and eventually achieved recognition in the fashion industry when asked to fill in for someone at an event attended by celebrities that went on to receive wide press coverage.

'Henrik', 20

Henrik is originally from Sweden but is now permanently living in London as a full time model. He was discovered while on a two week holiday with his family in London. Upon being approached, he spent much of the holiday getting test shots done for his book, learning to walk properly, going to fittings. Having such faith in his potential, the agency signed him before he went back to Stockholm and having graduated high school, immediately moved back to London. He is now currently signed to Models 1 in London, MIKAs in Stockholm and Scoop Models in Copenhagen.

'Simon', 18

Simon is originally from Manchester was discovered in the Trafford Centre in Manchester just over one year ago. He was discovered by a brand ambassador for Hunter footwear and has thus spent the majority of his short career working on their campaigns and editorial advertisements.

'Robert', 34

Robert grew up in New York where he studies at Parsons School of Design. His mother was also a fashion designer who owned a popular boutique in the Soho area of New York. He was inspired from an early age to become a designer after he saw how ladies that frequented his mother's store became emotional upon seeing their reflection in the mirror wearing her beautiful designs.

'Noel', 24

Having struggled for some time to break into high fashion, Noel has developed a close working relationship with brands Ovadia \& Sons as well as Sibling. While he does not appear to 'fit' with the luxury of brands such as Tom Ford or Gucci, his walk and look are said to be a perfect match for those high fashion knitwear brands and the slouchy, oversized trend of the moment.

'Jonny', 40

Jonny is a booker who spent some time in New York in the marketing department of DKNY. Having learned the ins and outs of fashion during his four years here, he moved to London to work for British Vogue as a contributor. Since then he has moved into casting work and now works predominantly as a casting director for various luxury brands.

'Fiona', 32

Fiona is an accomplished stylist who studies fashion design and trend analysis at Central St. Martins in London. Having graduated she undertook an internship with Alexander McQueen. Her dedication to her craft has made her a very popular freelance stylist with some of the most exclusive brands in London.

Adele, 43 
Adele is a theatre set designer by trade having studied theatre set design at University. She has designed sets for theatre companies across the UK most notably 'Much Ado About Nothing' at Shakespeare's Globe and A Christmas Carol at the Old Vic Theatre. For the last decade, she has been designing theatrical catwalk sets for fashion brands and has been a regular contributor to the LFW stage. 